\title{
ANÁLISIS ACADÉMICO JURISPRUDENCIAL SEDE JURISDICCIONAL DE PROTECCIÓN AL CONSUMIDOR*
}

\author{
JURISPRUDENTIAL ACADEMIC ANALYSIS \\ JURISDICTIONAL HEADQUARTERS OF \\ CONSUMER PROTECTION
}

SONIA ESPERANZA CASALLAS BAUTISTA**

LAURA VIVIANA MUÑOZ PEDRAZA***

JUAN CARLOS LOPEZ GONZÁLEZ ${ }^{* * * * *}$

MARÍA TERESA SALAMANCA TORRES ${ }^{* * * * * *}$

Fecha de recepción: 23 de marzo de 2018

Fecha de aceptación: 30 de octubre de 2018

Disponible en línea: 15 de marzo de 2019

Para Citar este artículo/To cite this article

Casallas Bautista, Sonia Esperanza, Muñoz Pedraza, Laura Viviana, López González, Juan Carlos \& Salamanca Torres, Maria Teresa, Análisis académico jurisprudencial sede jurisdiccional de protección al consumidor, 49 Rev.Ibero_ latinoam.Seguros, 269-314 (2018). https://doi.org:1011144/Javeriana.ris49.aajs

doi.org:1011144/Javeriana.ris49.aajs

Trabajo de investigación, co-ganador del primer puesto, presentado en representación de la Universidad de la Sabana para participar en el concurso organizado por la Asociación Colombiana de Derecho de Seguros (ACOLDESE) denominado: Investigación sobre las decisiones judiciales en materia de contrato de seguro adoptadas por la Superintendencia Financiera de Colombia.

** Administradora de Empresas, Especialista en Seguros y Seguridad Social de la Universidad de la Sabana, vinculada al Sector Asegurador desde hace más de 20 años, actualmente desempeño el cargo de Gerente Comercial en Itaú Corredor de Seguros Colombia S.A. ORCID: 0000-0003-4057-0991 Contacto: Sonia.casallas@hotmail.com.

*** Profesional en Finanzas y Negocios Internacionales de la Universidad de Compensar con Especialización en Seguros y Seguridad Social de la Universidad de la Sabana, trabaja en Organización Terpel S.A. como Analista de Riesgos y Seguros. ORCID: 0000-0002-8380-1078 Contacto: lauramupe@unisabana.edu.co.

**** Administrador de Empresas y Especialista en Seguros y Seguridad social de la Universidad de la Sabana, con 8 años de experiencia en el sector asegurador desempeñando diferentes Cargos en Empresas como Delima Marsh SA, Seguros Mundial y actualmente como Senior Underwriter Surety en Zurich

****** Abogada vinculada al sector asegurador hace veinticinco años, Especialista en Seguros y Seguridad Social de la Universidad de la Sabana. ORCID: 0000-0002-2830-9478 Contacto: mariasalto@unisabana.edu.co; terely73@gmail.com 


\section{RESUMEN}

La investigación adelantada por el grupo de alumnos de la Especialización de Seguros y Seguridad Social de la Universidad de la Sabana corresponde a una revisión y análisis bajo línea jurisprudencial de las Sentencias dictadas por la Delegatura de Protección al Consumidor Financiero de la Superintendencia Financiera de Colombia, en virtud del atributo legal que le fuera conferido mediante la Ley 1480 de 2011, con la creación de la Acción de Protección al Consumidor, contemplada en los artículos 57 y 58 (Estatuto del Consumidor) y luego incorporada en el artículo 24 del Código General del Proceso.

El análisis incluye un marco conceptual, destacando en este el entorno de la labor que realiza la Delegatura de Protección al Consumidor, los antecedentes de la función jurisdiccional y el marco jurídico de los temas atendidos; así como los fundamentos de las decisiones confrontados con la posición de otras corporaciones.

La metodología que se empleó para llevar a cabo dicho análisis jurisprudencial fue la lectura del contenido de las providencias de manera individual; así como la reproducción de audios de las actuaciones adelantadas en los procesos para lograr identificar los aspectos generales que usualmente la Delegatura utiliza para afrontar y resolver la controversia y luego descender al caso en concreto. Dichas decisiones corresponden a actuaciones realizadas entre el año 2012, hasta algunas del año 2017.

Los resultados del análisis permitirán evidenciar las diferentes posiciones jurisprudenciales que ha adoptado la Delegatura de Protección al Consumidor a lo largo del desarrollo de su facultad jurisdiccional.

Palabras clave: Acción de Protección; Estatuto del Consumidor; Sentencias Proferidas. 


\begin{abstract}
The research carried out by the Group of students from the specialization of insurance and Social security of the Universidad de la Sabana corresponds to one review and analysis under jurisprudential line of the rulings handed down by the delegates of protection consumer finance of the Financial Superintendent of Colombia, under the legal attribute that you was conferred by the law 1480 in 2011, with the creation of the action of Protection to the consumer, as referred to in articles 57 and 58 (Statute of the consumer) and then incorporated in article 24 of the General code of the process.
\end{abstract}

The analysis includes a conceptual framework, highlighting in this environment of the work being done by the delegates of protection to the consumer, the background of the judicial function and the legal framework of the treated topics; as well as the fundamentals of the decisions faced with the position of other corporations.

The methodology used to carry out such jurisprudential analysis was the reading of the contents of the orders individually; as well as the reproduction of audio of the proceedings carried out processes to achieve identify general aspects that usually the delegates used to tackle and resolve the dispute and then descend to the case in particular. These decisions correspond to actions carried out between the year 2012, until some of the year 2017.

The results of the analysis will allow evidence different jurisprudential positions adopted by the delegates of protection consumers throughout the development of their judicial faculty.

Keywords: Protection Action; Statute of the Consumer; Sentences Uttered

\title{
SUMARIO
}

INTRODUCCIÓN. 1. ACCIÓN DE PROTECCIÓN AL CONSUMIDOR FINANCIERO - MATERIA JURISDICCIONAL. 1.1. De la protección al consumidor financiero y de la relación de consumo. 1.2. Definición de consumidor financiero. 2. DEBER DE INFORMACIÓN. 2.1. Obligación de entregar el clausulado. 3. DE LA CADUCIDAD Y DE LA PRESCRIPCION DE LA ACCIÓN DE PROTECCIÓN AL CONSUMIDOR. 3.1. Caducidad de la acción de protección diferente a prescripción. 3.1.1. Caducidad. 3.2. Prescripción del contrato de seguro. 3.3. Interpretación de la prescripción cuando se trata de la cobertura de incapacidad total y permanente. 3.4. Interrupción de la prescripción. 4. CLÁUSULAS ABUSIVAS. 5. RETICENCIA E INEXACTITUD. 6. SEGURO DE VIDA - VIDA GRUPO DEUDORES. BIBLIOGRAFÍA. 



\section{INTRODUCCIÓN}

La presente investigación tuvo su origen en el ejercicio de elaboración de una línea jurisprudencial de las Sentencias dictadas por la Superintendencia Financiera de Colombia, en sede Jurisdiccional, atributo legal que le fuera conferido por el Legislador Colombiano mediante la expedición de la Ley 1480 de 2011, con la creación de la Acción de Protección al Consumidor, contemplada en los artículos 57 y 58 del Estatuto del Consumidor (Ley 1480 de 2011), y después incorporada en el artículo 24 del Código General del Proceso, con el objeto de se resolvieran de manera definitiva las controversias existentes entre consumidores financieros y entidades vigiladas por la mencionada Entidad relacionadas exclusivamente con el cumplimiento y ejecución del contrato financiero entre las partes celebrado.

De conformidad con lo expuesto, fue necesario en primera medida realizar un trabajo investigativo previo con el fin de obtener las decisiones proferidas por dicha Superintendencia, las cuales fue posible recaudar algunas mediante Sentencias escritas y otras en grabaciones de las audiencias que se adelantan con ocasión de dicha Acción.

Una vez recopilada la información, se procedió a su análisis mediante la lectura o la reproducción de los audios, para posteriormente pasar a un análisis individual de cada una de ellas, logrando identificar en primera medida los aspectos generales que usualmente la Delegatura utiliza para afrontar y resolver la controversia y luego descender al caso en concreto.

Cumplido lo anterior, se realizó un estudio de cuales Sentencias podrían ser agrupadas ya sea por tema o por el tipo de póliza, verificado lo anterior se llevó a cabo la compilación que hoy se capitula en el presente trabajo.

Es preciso señalar que el estudio jurisprudencial realizado tiene como soporte las Sentencias dictadas por la Superintendencia Financiera de Colombia en sede Jurisdiccional, Juez Especialista en materias de Derecho Financiero, Bursátil y asegurador, Delegatura que si bien hace parte de la estructura de la precitada Superintendencia y se encuentra directamente ligada al Despacho del Superintendente Financiero de Colombia, esta revestida de una importante independencia de las demás áreas y direcciones 
de la entidad, ello es así para garantizar la imparcialidad que le debe caracterizar a todo Juez de la Republica y el debido proceso.

Este análisis jurisprudencial forma parte un ejercicio académico orientado a la investigación, entendimiento e interpretación de la evolución de la postura de la Delegatura para Funciones Jurisdiccionales dentro del desarrollo de su facultad jurisdiccional de protección al consumidor, que fue otorgada por el legislador colombiano en el año 2012 y con ello, poder dar a conocer su posición en los fallos en materia de seguros comprendidos en el periodo $2012-2016$.

El enfoque fundamental de este ejercicio de análisis jurisprudencial no es otro que la exteriorización de los pronunciamientos emanados por la Superintendencia Financiera de Colombia en el ámbito jurisdiccional a efectos de poder conocer un poco más de cerca su concepción y fundamentación; así como, los criterios que son pilares de dichas decisiones, por lo que, es un viaje corto pero verídico en temas de actualidad del sector asegurador que podrán ser observados frente a otros jueces naturales del orden civil y constitucional, por lo que aquí es el punto de partida de dicha exploración.

\section{ACCIÓN DE PROTECCIÓN AL CONSUMIDOR FINANCIERO - MATERIA JURISDICCIONAL}

Al respecto, es preciso indicar que el soporte legal de la Acción de Protección al Consumidor se encuentra establecido, regulado o contemplado en principio en el artículo 116 de la Constitución Política y desarrollado en el artículo 57 de la Ley 1480 de 2011, a cuyo tenor:

En aplicación del artículo 116 de la Constitución Política, los consumidores financieros de las entidades vigiladas por la Superintendencia Financiera de Colombia podrán a su elección someter a conocimiento de esa autoridad, los asuntos contenciosos que se susciten entre ellos y las entidades vigiladas sobre las materias a que se refiere el presente artículo para que sean fallados en derecho, con carácter definitivo y con las facultades propias de un juez. 
En desarrollo de la facultad jurisdiccional atribuida por esta ley, la Superintendencia Financiera de Colombia podrá conocer de las controversias que surjan entre los consumidores financieros y las entidades vigiladas relacionadas exclusivamente con la ejecución y el cumplimiento de las obligaciones contractuales que asuman con ocasión de la actividad financiera, bursátil, aseguradora y cualquier otra relacionada con el manejo, aprovechamiento inversión de los recursos captados del público. La Superintendencia Financiera de Colombia no podrá conocer de ningún asunto que por virtud de las disposiciones legales vigentes deba ser sometido al proceso de carácter ejecutivo. Tampoco podrán ser sometidas a su competencia acciones de carácter laboral.

Los asuntos a los que se refiere el presente artículo se tramitarán por el procedimiento al que se refiere el artículo 58 de la presente ley.

PARÁGRAFO. Con la finalidad de garantizar la imparcialidad y autonomía en el ejercicio de dichas competencias, la Superintendencia Financiera de Colombia ajustará su estructura a efectos de garantizar que el área encargada de asumir las funciones jurisdiccionales asignadas por la presente ley cuente con la debida independencia frente a las demás áreas encargadas del ejercicio de las funciones de supervisión e instrucción.

Por su parte, el artículo 58 de la precitada ley 1480 de 2011 dispone que:

"Los procesos que versen sobre violación a los derechos de los consumidores establecidos en normas generales o especiales en todos los sectores de la economía, a excepción de la responsabilidad por producto defectuoso y de las acciones de grupo o las populares, se tramitarán por el procedimiento verbal sumario, con observancia de las siguientes reglas especiales:

1. La Superintendencia (...) tiene competencia en todo el territorio nacional y reemplaza al juez de primera o única instancia competente por razón de la cuantía y el territorio.

\section{2. (...).}

3. (...) las controversias netamente contractuales, a más tardar dentro del año siguiente a la terminación del contrato, (...) En cualquier caso 
deberá aportarse prueba de que la reclamación fue efectuada durante la vigencia de la garantía.

4. No se requerirá actuar por intermedio de abogado. Las ligas y asociaciones de consumidores constituidas de acuerdo con la ley podrán representar a los consumidores. Por razones de economía procesal, la Superintendencia de Industria y Comercio podrá decidir varios procesos en una sola audiencia. "르

En desarrollo de la facultad jurisdiccional atribuida por esta ley, la Superintendencia Financiera de Colombia podrá conocer de las controversias que surjan entre los consumidores financieros y las entidades vigiladas relacionadas exclusivamente con la ejecución y el cumplimiento de las obligaciones contractuales que asuman con ocasión de la actividad financiera, bursátil, aseguradora y cualquier otra relacionada con el manejo, aprovechamiento inversión de los recursos captados del público.

La Superintendencia Financiera de Colombia no podrá conocer de ningún asunto que por virtud de las disposiciones legales vigentes deba ser sometido al proceso de carácter ejecutivo. Tampoco podrán ser sometidas a su competencia acciones de carácter laboral.

Los asuntos a los que se refiere el presente artículo se tramitarán por el procedimiento al que se refiere el artículo 58 de la presente ley". $\underline{.7}$

En armonía con lo anterior, el artículo 24 del Código General del Proceso dispone que "la Superintendencia Financiera de Colombia conocerá de las controversias que surjan entre los consumidores financieros y las entidades vigiladas relacionadas exclusivamente con la ejecución y el cumplimiento de las obligaciones contractuales que asuman con ocasión de la actividad financiera, bursátil, aseguradora y cualquier otra relacionada con el manejo, aprovechamiento e inversión de los recursos captados del público" ello al tenor de lo señalado en el artículo 24 del Código General del Proceso.

Así las cosas, atendiendo el atributo jurisdiccional otorgado excepcio-

26 Sentencia 2013-0130 Superintendencia Financiera de Colombia

27 Sentencia 2014-0846 Superintendencia Financiera de Colombia 
nalmente a las entidades administrativas, en los términos del artículo 116 Constitucional, el Legislador le otorgó Jurisdicción a la Superintendencia Financiera de Colombia para conocer de manera definitiva las controversias contractuales existentes entre consumidores financieros y entidades vigiladas por esa Superintendencia, facultad que cobró vigencia el 12 de octubre de 2011.

De otra parte, es preciso indicar que antes de la expedición de la Ley 1480 de 2011, si bien ya se le habían otorgado facultades Jurisdiccionales tanto a la Superintendencia Bancaria y de Valores, las mismas habían sido declaradas inconstitucionales por parte de la Corte Constitucional, argumentando que no se garantizaba (en esa oportunidad) que el área jurisdiccional pudiera ser independiente financiera y estructuralmente para garantizar la imparcialidad, lo que se solventó (hoy en día) con la ubicación de la Delegatura en el mapa de la Superintendencia como una actividad misional autónoma que depende tan solo de la oficina del Superintendente Financiero.

\subsection{De la protección al consumidor financiero y de la relación de consumo.}

En lo que tiene que ver con la protección al consumidor, de conformidad con las Sentencias dictadas en los procesos 2012-0016 y 2014-0073, está dirigida a poner en igualdad de condiciones a los consumidores y las entidades, la cual se materializa eliminado las barreras que imponen la asimetría de la información y el poder económico del uno frente al otro.

Dicha posición adoptada por Delegatura tiene respaldado en el fallo de la Sala de Casación de la Corte Suprema de Justicia, quien manifestó que "la relación de consumo constituye una particular categoría que surge entre quienes se dedican profesionalmente a elaborar o proveer bienes o prestar servicios con quien los adquiere con el fin de consumirlos, y es precisamente el consumidor, quien, por encontrarse en condiciones de vulnerabilidad económica y de desequilibrio, es destinatario de una especial protección normativa: por supuesto que la profesionalidad del productor. Lo sitúan en un plano de innegable ventaja negocial que reclama la intervención de legisladores y jueces con miras a restablecer el equilibrio perdido. Las más relevantes reivindicaciones de los con- 
sumidores apuntan a la necesidad de reformar las reglas de formación del contrato de modo que abarquen las nuevas realidades negociable, concretamente, la contratación masiva; hacia la apremiante necesidad de consagrar un periodo de reflexión seguido del derecho de arrepentimiento del consumidor; a vigorizar la tutela de éste en relación con los vicios del consentimiento frente a las dificultades propias de la contratación masiva; a destacar la importación de la publicidad y en general, de la información en los procesos contractuales; a regular lo concerniente con las clausulas limitativas de responsabilidad; a robustecer el régimen de responsabilidad del fabricante y los proveedores, entre otras..." 1

Así mismo, en materia de protección al consumidor, la Delegatura ha señalado que “... resulta indispensable (...) señalar que la acción de protección al consumidor, sin bien impone unas condiciones más favorables al mismo, no lo releva per se del cumplimiento de sus obligaciones contractuales, salvo que en efecto exista alguna circunstancias palpable que genera la imperiosa necesidad que la Delegatura proceda a equilibrar la evidente disparidad en la que se encuentran los extremos contractuales, tales situaciones se observan con las cláusulas oscuras o contradictorias, entre otras, situación que son analizadas para cada caso en particular y que no observa esta entidad en la presente acción.

De conformidad con lo anterior, es preciso indicar a modo de una breve conclusión, que la Delegatura efectúa un análisis previo de la calidad que deben ostentar las partes en el litigio; en lo que tiene que ver con la entidad demandada debe ser una entidad vigilada por la Superintendencia y en lo que respecta al demandante debe tener una relación contractual con la entidad aseguradora y ostentar la calidad de consumidor financiero conforme la categorización realizada por la Corte Constitucional, la cual está orientada a que el cliente adquiera un bien, en este caso un seguro, con el fin de consumirlo, es decir que no haga parte de su cadena de producción o comercialización, sino que sea para el consumo propio, para amparar sus propios riesgos, y que exista una condición de asimetría y vulnerabilidad económica frente a la compañía.

Por lo anterior, se vislumbra que el Legislador mediante la expedición de la Ley 1480 de 2011 en armonía con la reforma financiera de la Ley 1328

1 Jurisdicción ordinaria sala de casación civil - sentencia del 30 de abril de 2009 
de 2008, le impuso a la entidad vigilada no solamente el deber de demostrar el cumplimiento contractual a la entidad aseguradora demandada sino que debe acreditar el incumplimiento de las obligaciones contractuales de la parte actora, ello para lograr la exoneración de responsabilidad contractual debatida en la acción de protección al consumidor.

\subsection{Definición de consumidor financiero.}

Para efectos de estudiar la definición de consumidor financiero, la Delegatura para Funciones Jurisdiccionales ha tenido en cuenta la enunciación contenida en la Ley 1328 de 2009 entendiendo como tal todo cliente, usuario o cliente potencial de las entidades vigiladas.

Sobre tal aspecto, en las Sentencias 2012-0016 y 2014-0073 se hizo alusión a la definición de consumidor indicando que: "Definición de consumidor financiero: El carácter de consumidor financiero, de cara a la Ley 1328 de 2009 y frente a la especial consagración de la competencia de la SUPERINTENDENCIA FINANCIERA DE COLOMBIA en su facultad jurisdiccional, presupone tres condiciones:

I. La interrelación de dos sujetos en condiciones de desigualdad, en donde uno de ellos es el sujeto que concurre al mercado para la adquisición de bienes o servicios o la utilización de estos.

II. El sujeto, persona natural o jurídica, se denomina consumidor financiero siempre que, de conformidad con la ley 1328, "acuda a una entidad vigilada de la Superintendencia Financiera para el suministro de bienes o servicios, en desarrollo de su objeto social, o la prestación de los servicios por ellas ofrecidos exista una relación contractual o legal con la entidad vigilada"; en el primer caso, aún en "fase previa de tratativas preliminares".

III. Y, un tercer elemento es que el consumidor financiero que acude a ejercer la acción de protección al consumidor ante la Superintendencia Financiera de Colombia, en ejercicio de funciones jurisdiccionales, debe invocar una relación contractual en la que sea parte, beneficiario o víctima, cuyas obligaciones han sido incumplidas o defectuosamente realizadas. 
Respecto del primer rasero, esto es, la situación de desigualdad que necesariamente debe presentarse entre consumidores y productores, en nuestro caso, entidades vigiladas, encuentra esta Delegatura, con fundamento en la doctrina constitucional, que ante la dificultad que pudiera presentarse para establecer si una determinada persona se encuentra o no en una situación de desequilibrio frente a su contraparte, pues dicha asimetría obedece a criterios de carácter subjetivo que dificilmente pueden estandarizarse, existen situaciones que pueden clarificar la configuración de asimetrías en la relación de consumo, estás son: i) la capacidad de negociación de las partes al momento de suscribir un contrato o pactar las condiciones en que se ha de adquirir determinado bien o servicio y, ii) el grado de especialidad y conocimiento de las partes sobre la materia o aspectos involucrados en el proceso de producción del bien o servicio que se adquiere.

En lo atinente a la capacidad de negociación de las partes, se tiene que aunque no existe una disposición particular que dé cuenta de esa aptitud, lo cierto es que el legislador advirtió que las personas que concurren al mercado para adquirir bienes o servicios en busca de la satisfacción de sus necesidades, no tienen la capacidad de negociar con los proveedores y productores, en el caso concreto, las entidades financieras, aseguradoras o bursátiles, las condiciones en que se van a adquirir los bienes o servicios que estos ofrecen, sino que por regla general, a estos solo les corresponde decidir si se adhieren o no a las que de manera previa y unilateral se han fijado al respecto.

Superado este criterio de envergadura constitucional, corresponde al operador judicial, determinar adicionalmente, si el sujeto que reclama una protección especial derivada de su condición de consumidor cumple o no con los demás requisitos o criterios antes señalados, es decir "(i) acuda a una entidad vigilada de la Superintendencia Financiera para el suministro de bienes o servicios, en desarrollo de su objeto social, o la prestación de los servicios por ellas ofrecidos y, ii) exista una relación contractual o legal con la entidad vigilada;" en el primer caso, "aún en "fase previa de tratativas preliminares".

De esta manera, encuentra esta Delegatura que la categoría de consumidor financiero se configura previo el cumplimiento concurrente de cada 
uno de los criterios de caracterización antes señalados, los cuales deben considerarse de manera aislada para cada uno de los casos de que conoce este Despacho en ejercicio de la Acción de Protección al Consumidor, la cual, como su nombre lo indica se encuentra delimitada en su aplicación, entre otras cosas, por la existencia de un consumidor que demande del aparato jurisdiccional una especial protección?

\section{DEBER DE INFORMACIÓN}

Ahora bien, dentro del contexto de los fallos emitidos por la Delegatura se encuentra también expresada su posición frente al "deber de información", el cual, tiene como pilar la necesidad que el consumidor reciba una información cierta, veraz y oportuna, a fin de menguar el desequilibrio existente entre las entidades financieras y aseguradora con el consumidor financiero.

Sobre este aspecto, dicha entidad en su labor jurisdiccional ha señalado reiteradamente en sus fundamentos que:

“(...) el acceso a la información adquiere mayor relevancia si se tiene en cuenta que en relaciones de consumo que surgen tanto de este tipo de negocio jurídico como de cualquier otro, el derecho de recibir información oportuna, clara, precisa e idónea es un derecho del consumidor, cuya prevalencia tiene sus cimientos desde la Constitución misma, cuando en su artículo 78 estatuyó que "la ley regulará el control de calidad de bienes y servicios ofrecidos y prestados a la comunidad, así como la información que debe suministrarse al público en su comercialización", postulado que se desarrolló en el título primero de la Ley 1328 de 2009, especificamente estableciendo un régimen de protección al consumidor financiero, en el que se destaca, dentro de la contratación financiera, la obligación según la cual la información debe ser "cierta, suficiente y oportuna" y en particular que la que "se suministre previamente a la celebración del contrato, deberá permitir y facilitar la adecuada comparación de las distintas opciones ofrecidas en el mercado" para que "el consumidor comprenda el contenido y funcionamiento de la

2 Sentencia 2014-0073 de la Superintendencia Financiera de Colombia 
relación establecida para suministrar un producto o servicio”, al punto que el incumplimiento de la obligación da derecho al consumidor financiero "de finalizar el contrato sin penalidad alguna, sin perjuicio de las obligaciones que según el mismo contrato deba cumplir" (artículos 9 y 10).

De allí, la importancia no sólo de la claridad de las cláusulas contenidas en la póliza, como el caso de la exclusión que se pretende enrostrar al demandante, sino además, de que estas sean conocidas por el asegurado en este caso, para que manifieste libremente su consentimiento en señal de aceptación, máxime tratándose de un clausulado elaborado por la aseguradora, que en últimas supera los límites de la consensualidad del contrato de seguro".

Posición adoptada en el expediente 2014-079 reiterada en 2016-0198.

En tal sentido, es igualmente necesario precisar a efectos de no perder de vista el enfoque y desarrollo del deber de información, que este ha sido consignado en la Circular Básica Jurídica ${ }^{3}$ de la SUPERINTENDENCIA FINANCIERA DE COLOMBIA, y en la que se resalta que "cuando el deudor opte por su adhesión como asegurado a la póliza tomada por la entidad de crédito, esta deberá suministrarle información sobre los requisitos y el procedimiento para el perfeccionamiento de su inclusión”.

En armonía con lo anterior, en el expediente 2013-0475 donde se estudia el deber de información de la entidad bancaria en una póliza grupo deudores que "Es la oportunidad para precisar que el banco (.....), actuó en el contrato que origina la acción de la referencia, como tomador del mismo, lo que le da la calidad de parte y en todo caso, excluye la actividad de intermediación o representación que invoca el apoderado actor y que el artículo 101 de la Ley 510 de 1999 otorga a las agencias y agentes de seguros. Ahora bien, en lo que respecta al deber de información en los seguros de vida cuando el tomador de la póliza es la entidad bancaria, la Circular básica Jurídica 007 de 1996, Título I, Capítulo VI señala que "cuando el deudor opte por su adhesión como asegurado a la póliza tomada por la entidad de crédito, esta deberá suministrarle información sobre los requisitos y el procedimiento para el perfeccionamiento de su inclusión.". ${ }^{4}$

3 Circular Básica Jurídica, Título I, Cap. VI

4 Sentencia 2013-0345 del 28 de enero de 2014 Superintendencia Financiera 
Por ello, es importante integrar las posiciones que sobre el caso expresan otros juzgadores y que han sido aporte dentro de los fallos proferidos por parte de la Delegatura, como lo es, lo expresado por la Corte Constitucional en Sentencia T-015/12, quien adopta en sus fundamentos la posición esbozada por la Corte Suprema de Justicia - Sala de Casación Civil y Agraria en providencia de fecha 2 de mayo de 2000논, al señalar que: "las condiciones generales de contratación, denominadas comúnmente condiciones o cláusulas generales del negocio o del contrato, son la columna vertebral de la relación asegurativa y junto con las condiciones o cláusulas particulares del contrato de seguros conforman el contenido de éste negocio jurídico, o sea el conjunto de disposiciones que integran y regulan la relación. Esas cláusulas generales, como su propio nombre lo indica, están llamadas a aplicarse a todos los contratos de un mismo tipo otorgados por el mismo asegurador o aún por los aseguradores del mismo mercado y están destinadas a delimitar de una parte la extensión del riesgo asumido por el asegurador de tal modo que guarde la debida equivalencia con la tarifa aplicable al respectivo seguro y, de otra, a regular las relaciones entre las partes vinculadas al contrato, definir la oportunidad y modo de ejercicio de los derechos y observancia de las obligaciones o cargas que de él dimanan...De otro lado, las condiciones particulares del contrato de seguro se elaboran de manera individual y especifica para cada contrato y de manera conjunta entre el asegurador y el tomador y reflejan asimismo, pero en forma especifica para el negocio acordado, la voluntad de los contratantes".

Importa precisar, que la Delegatura en varias de sus providencias ha fundado sus decisiones adoptando la posición de la Corte Constitucional en Sentencia T-136 de 2013 "el acceso completo, veraz y oportuno a la información -que es una condición elemental, inherente a toda actividad de consumo- adquiere especial trascendencia en el marco del sistema financiero, en razón a los contratos de adhesión que suelen ofrecer las entidades vigiladas en el mercado, a la complejidad de los términos contractuales que se manejan y al estado de indefensión en que se encuentran los usuarios. Siendo así, la información es una de las herramientas clave para empoderar al ciudadano en su ejercicio contractual, tanto antes de la celebración de un contrato, como durante su ejecución

$5 \quad$ CSJ - Sala Casación Civil y Agraria - Expediente No. 6291 - 2 mayo de 2000 - M.P. Jorge Santos Ballesteros 
$y$ aún después de la terminación del mismo, con el fin de precaver que la libertad contractual se emplee abusivamente en detrimento de otros derechos fundamentales. Es por ello que cualquier restricción injustificada al acceso a la información debe entenderse como una práctica abusiva, propiciada por el poder dominante del que gozan las entidades aseguradoras y bancarias". $\underline{6}$

Así las cosas, el deber de información se ve reflejado en cada uno de los contratos de seguros que se comercializan en el Sector Asegurador, como lo hace ver la Superintendencia Financiera de Colombia frente a las pólizas colectivas al referirse dentro de los apartes de una de sus providencias, indicando que "atendiendo la nueva realidad jurídica que nos cobija, en punto a la inteligibilidad y aplicabilidad de los negocios jurídicos celebrados entre el tomador de la póliza colectiva o de grupo, (....) y la aseguradora (.....), se deviene una suerte de efectos jurídicos que pueden aparejar consecuencias adversas a los asegurados, que dicho sea de paso, a la luz de la ley 1328 de 2009 también han de ser considerados como consumidores financieros, puesto que estos últimos han de soportar las consecuencias jurídicas que irradia la actividad negocial desplegada entre los a priori denominados partes del contrato aseguraticio.

Por tanto, conviene examinar la información que en el caso de marras le fue brindada a la señora (.....), en calidad de asegurada, por parte de la entidad aseguradora, bajo la perspectiva que la actividad que desarrolla dicha entidad ha sido declarada en múltiples oportunidades como una actividad de interés público."

No obstante lo expresado por la Delegatura para Funciones Jurisdiccionales, se resalta también dentro del estudio de deber de información, en otro aspecto relevante, al hacer referencia al nivel de escolaridad del demandante. Entorno a ello, ha indicado que "no sobra resaltar que para proceder a la suscripción de ese documento, el asegurado pudo leer e informarse sobre su contenido y alcance (práctica de protección propia de los consumidores financieros de acuerdo con lo establecido por el artículo $6^{\circ}$ de la Ley 1328 de 2009), máxime cuando en la audiencia el demandante explicó que pese al nivel de escolaridad de su padre, destacó

6 Corte Constitucional Sentencia T-136 de 2013 
su calidad de comerciante con una amplia experiencia crediticia con el (.....), por lo que no podía resultarle extrañas este tipo de operaciones financieras y la documentación que debía suscribir para su perfeccionamiento" Sentencia 2015-1370

En lo que respecta al deber de información por parte del consumidor financiero, entre otras la Sentencia proferida en el proceso 2013-0699 señaló que "la obligación contractual, a cargo de los consumidores financieros, de suministrar información cierta, a las entidades vigiladas, así como de actualizar los datos que así lo requieran, no resulta abusiva, desproporcionada o caprichosa, sino que se encuentra acorde con el régimen de protección a los consumidores financieros y con las disposiciones relativas a la prevención de actividades relacionadas con el lavado de activos y la financiación del terrorismo. En estos casos, el Banco debe requerir la información al consumidor financiero, para que este pueda adoptar las medidas del caso, bien para actualizar sus datos o para redirigir sus dineros a otra cuenta o entidad".

\subsection{Obligación de entregar el clausulado.}

Así mismo, ha destacado que en desarrollo del deber de información en cabeza de la Aseguradora se encuentra la obligación de entregar el clausulado, aspecto este donde ha dejado clara su posición y sobre lo cual, no admite interpretación diferente a lo expuesto por la misma en sede jurisdiccional, al manifestar que "en tales términos, vale la pena preguntarse si le resulta oponible al demandante unas condiciones que este aduce no haber conocido, y sobre las cuales (....) no acreditó en el plenario su entrega al hoy demandante, cuando el siniestro ocurrió con anterioridad a la entrega del condicionado. Interrogante que ha de contestar la Delegatura negativamente, puesto que en el expediente no obra prueba siquiera sumaria de que al demandante se le hubiere entregado información, cierta, veraz y oportuna respecto del clausulado aplicable al producto que el demandante adquirió en la compañía de financiamiento, ni mucho menos se allegó el comprobante del medio y la fecha de entrega de las condiciones de la póliza al demandante que le fuera requerido a la pasiva desde el auto que fijó fecha para audiencia el cual a su vez le fue insistido en la presente audiencia, sin que sea de recibo la respuesta de la representante legal de la entidad demandada en 
el interrogatorio de parte que con el formato de vinculación a la tarjeta de crédito se supla la entrega de los mismos al cliente, o que se entienda que el clausulado de la póliza se entienda como un solo documento o que se integre al formato de vinculación de tarjeta de crédito, pues del mismo, el cual obra a folio 91, tan solo aparece la autorización que dio el cliente para que (...) adquiriera la póliza de vida grupo deudores con (.....), pero no aparece en su texto mención alguna de los amparos, exclusiones y demás condiciones de la póliza”. Expediente 2014-1064

Así las cosas, la Delegatura utiliza varias herramientas para dar un tratamiento igualitario a las partes del proceso; una de ellas corresponde al deber de información, el cual no solamente recae en hombros de la entidad cuando se le exige que a la fecha de celebración del contrato, se le suministre al consumidor una asesoría y una información, clara, veraz y efectiva, y que las condiciones de la póliza le sean entregadas al cliente dentro del mes siguiente a la celebración del contrato. Vale la pena señalar en este punto, que es válido argumentar que la afirmación se encuentra debidamente publicada en la página de internet o está disponible en las sucursales de la aseguradora, siempre y cuando se le facilite al demandante un mecanismo para que pueda acceder a ellas.

Es preciso señalar que no es válida la manifestación de que las condiciones de la póliza se encuentran depositadas en la Superintendencia Financiera para que el demandante allí las consulte, pues como se advirtió, deben ser entregadas o puestas a disposición del demandante. Al respecto, se puede leer el fallo 2016-1480.

Sin embargo, el deber de información también lo es de la parte demandante, quien debe no solamente interesarse respecto del producto que va a adquirir, sino que le asiste la obligación de leer el clausulado del documento que está suscribiendo y en caso de no entenderlo o de existir duda acreditar que le informó a la demandada su inconformidad con el producto, sin que en ningún caso pueda indicar que no leyó el clausulado. (Fallo 2015-0819).

Dentro de dicho contexto se ha desarrollado una posición generalizada entre los diferentes actores judiciales, pues todos, han coincidido en la necesidad de hacer énfasis a través de sus fallos en aspectos de 
gran relevancia como es la elaboración y determinación de textos claros y precisos, sumado al deber de información que tienen las compañías de seguros y sus intermediarios. Es así, que la Corte Constitucional en lo relacionado con los clausulados ha reiterado que "las condiciones generales de contratación, denominadas comúnmente condiciones o clausulas generales del negocio o del contrato, son la columna vertebral de la relación asegurativa y junto con las condiciones o clausulas particulares del contrato de seguros conforman el contenido de este negocio jurídico o sea el conjunto de disposiciones que integran y regulan la relación. esas cláusulas generales, como su propio nombre lo indica están llamadas a aplicarse a todos los contratos de un mismo tipo otorgados por el mismo asegurador o aun por los aseguradores del mismo mercado y están destinadas a delimitar de una parte la extensión del riesgo asumido por el asegurador de tal modo que guarde la debida equivalencia con la tarifa aplicable al respectivo seguro y de otra a regular las relaciones entre las partes vinculadas al contrato, definir la oportunidad y modo de ejercicio de los derechos y observaciones de las obligaciones o cargas que dé el dimanan (....) de otro lado, las condiciones particulares del contrato de seguro se elaboran de manera individual y especifica para cada contrato y de manera conjunta entre el asegurador y el tomador y reflejan asimismo, pero en forma especifica para el negocio acordado, la voluntad de los contratantes"

Posición que también ha sido adoptada en igual sentido por la $\mathrm{Su}-$ perintendencia Financiera de Colombia, buscando ser el guardián y protector de los Asegurados como parte débil en la relación contractual que se presenta.

\section{DE LA CADUCIDAD Y DE LA PRESCRIPCIÓN DE LA ACCIÓN DE PROTECCIÓN AL CONSUMIDOR}

\subsection{Caducidad de la acción de protección diferente a prescripción.}

Es conveniente de entrada realizar un breve análisis de la prescripción y caducidad, señalando que la posición de la Delegatura ha sido clara al

7 Sentencia T-015/12 de la Corte Constitucional 
indicar que la prescripción se rige conforme las condiciones generales dispuestas en el Código de Comercio, sin que se modifique o se aplique en forma diferente las directrices ya recorridas, las cuales a su vez tienen soporte en la actual Jurisprudencia de la Corte Suprema de Justicia. Como prueba de lo anterior, los fallos que se relacionan más adelante acreditan la posición adoptada.

\subsubsection{Caducidad}

Ahora, en lo que tiene que ver con la caducidad, desde el año 2012 hasta el mes de enero de 2016 se entendió que la misma correspondía al término contemplado en el numeral 3 del artículo 58 de la Ley 1480, es decir que la demanda se debía interponer a más tardar dentro del año siguiente a la terminación del contrato, bajo el entendido que la acción ejercida es la contractual, sin que en nada afecte si el siniestro hubiere ocurrido en un término superior, pues si el contrato se encuentra vigente la Delegatura se encuentra habilitada para conocer y resolver la controversia, cosa distinta sucede si la demanda se interpone superado el término de 1 año contado a partir de la terminación del contrato, eventualidad en la que si prospera la caducidad.

No obstante lo anterior, la posición de la caducidad en el año 2015 varió, atendiendo lo instruido por el Tribunal Superior de Bogotá en providencia dictada el 21 de enero de 2016 en el proceso 1100131 99-001-2015-01185-01, en el sentido de que el nombre o la denominación no debe ser de caducidad sino de prescripción, con las consecuencias procesales que ello conlleva, pero aprobando el soporte sustancial de dicha figura, es decir que la demanda se interponga a más tardar en el término de 1 año siguiente a la terminación del contrato de seguro, conforme lo contempla el precitado numeral 3 del artículo 58 de la Ley 1480 de 2011, para tal efecto se puede tener en cuenta el Fallo dictado en el proceso 2015-1688.

Así las cosas, adentrándonos en el tema propuesto, la Delegatura enfila su enfoque y estudio como juez natural frente a la Prescripción y Caducidad, señalando que la caducidad corresponde a aquel elemento temporal para interponer la acción de protección al consumidor conforme lo señala el numeral $3^{\circ}$ del artículo 58 de la Ley 1480, norma que dispone que 
"Las demandas para efectividad de garantía, deberán presentarse a más tardar dentro del año siguiente a la expiración de la garantía y las controversias netamente contractuales, a más tardar dentro del año siguiente a la terminación del contrato, En los demás casos, deberán presentarse a más tardar dentro del año siguiente a que el consumidor tenga conocimiento de los hechos que motivaron la reclamación. En cualquier caso deberá aportarse prueba de que la reclamación fue efectuada durante la vigencia de la garantía".

A partir de lo expuesto, se ha concluido que la demanda se debe presentar a más tardar dentro del año siguiente a la terminación del contrato de seguro. A manera de ejemplo, si el contrato terminó su vigencia el 31 de diciembre de 2015, la demanda, en sede Jurisdiccional debe presentarse a más tardar el día 31 de diciembre de 2016.

De otra parte, si el contrato de seguro que origina la controversia, se encuentra vigente al momento de la presentación de la demanda, la Delegatura será competente, pues se encuentra legal y contractualmente habilitada, sin importar que la ocurrencia del hecho objeto de demanda hubiere tenido lugar en un tiempo superior a 1 año, ello toda vez que en tratándose de controversias netamente contractuales la demanda deberá presentarse "a más tardar dentro del año siguiente a la terminación del contrato", sin que afecte el conocimiento o no de los hechos por parte del demandante, pues si el contrato permanece vigente, es decir, si no se ha terminado, no opera la figura de la Caducidad, sin importar la fecha de ocurrencia del siniestro.

También se puede concluir, conforme lo señalado en el Fallo dictado en el proceso 2014-0143, que comoquiera que la Ley 1480 de 2011 entró en vigencia el 12 de abril de 2012, para las controversias sometidas a conocimiento de la Delegatura para Funciones Jurisdiccionales y cuya ocurrencia hubiere tenido lugar antes de la entrada en vigencia de la Ley, el término de caducidad tan solo se puede empezar a contar a partir del 12 de abril de 2013, posición reiterada en el expediente 2014-0638, 2014-0825.

Así mismo, y como se indicó en precedencia, el numeral $3^{\circ}$ del artículo 58 de la Ley 1480 de 2011, para la promoción de la Acción de Protección al Consumidor, la Delegatura inicialmente había entendido que se trataba 
de un término de caducidad y no de prescripción, sin embargo, dicha concepción cambió, pues se acudió a lo señalado por el Tribunal Superior del Distrito Judicial de Bogotá - Sala Civil, dentro del proceso radicado 1100131 99-001-2015-01185-01, Providencia del 21 de enero de 2016, Magistrada Sustanciadora Julia María Botero Larrarte, quien manifestó que "tal interpretación no se ajusta a las reglas establecidas por la jurisprudencia para establecer cuándo un término legal puede establecerse como caducidad, esto es: (i) cuando la ley así lo indica o (ii) cuando el legislador consagra un lapso para ejercer determinada acción, último caso en el cual por vía jurisprudencial, se ha permitido entender como de caducidad; sobre el caso en estudio indicó que, "si bien es cierto, el numeral $3^{\circ}$ del artículo 58 de la Ley 1480 de 2011, al cual acudió, no hace alusión a una figura en concreto, y por ende, podría decirse que se refiere a una caducidad de la acción, como en efecto se declaró; también lo es, que de forma posterior, especificamente en el numeral $6^{\circ}$ de la misma disposición, el legislador optó por la figura de la prescripción de la acción, regulación de índole especial que debe primar y la cual no puede ser declarada de oficio".

Respetando el precedente jurisprudencial antes mencionado, el Juez ha recogido los argumentos expuestos de manera general por el Tribunal al indicar que "la posición que hasta entonces había aplicado, en el sentido de interpretar que el término establecido en el numeral $3^{\circ}$ del artículo 58 que se viene analizando, era de caducidad. Sin embargo, bajo el entendido dado por el Superior, se trata de un término de prescripción. Sobre este punto, si bien la excepción planteada por la pasiva se denominó como de caducidad, lo cierto es que los supuestos fácticos que la soportan hacen relación al término para el ejercicio de la acción, cumpliendo con la exigencia del término prescriptivo de ser invocada como medio de defensa para proceder a su análisis, razón por la cual la Delegatura, procederá al estudio de la excepción citada, hecha la anterior precisión”. (Fallo 2015-1688)

Es por ello que en las consideraciones de los fallos esta entidad en sede jurisdiccional ha declarado la prosperidad de la excepción planteada, pero bajo la interpretación dada por el Tribunal Superior de Bogotá en la decisión ya indicada. 


\subsection{Prescripción del contrato de seguro}

En lo que respecta al tema de la Prescripción de la Acción, la Superintendencia Financiera de Colombia ha señalado que "como punto de partida, cabe advertir que las pretensiones que se ventilan en ejercicio de la acción de protección al consumidor tienen naturaleza declarativa $y$, en tal virtud en cada caso debe analizarse el derecho comprometido, dado que la Ley ha establecido términos de prescripción, siendo relevante advertir que con el contrato que involucra la presente acción se cuenta con el término de prescripción consagrado en el artículo 1081 del Código de Comercio. Fallo 2012-0041, reiterado en el 2013-0282, 2013-0553, 2014-0402.

En lo que tiene que ver con el análisis del artículo 1081 la mencionada Entidad señala que "al tenor de lo dispuesto por el artículo citado, "La prescripción de las acciones que se derivan del contrato de seguro o de las disposiciones que lo rigen podrá ser ordinaria o extraordinaria ... LLa prescripción ordinaria será de dos años y empezará a correr desde el momento en que el interesado haya tenido o debido tener conocimiento del hecho que da base a la acción... La prescripción extraordinaria será de cinco años, correrá contra toda clase de personas y empezará a contarse desde el momento en que nace el respectivo derecho (...). Estos términos no pueden ser modificados por las partes." Fallo 2014-0881

Así las cosas, se tiene que la institución de la prescripción es un mecanismo implementado por el legislador para dotar de certeza jurídica las relaciones contractuales de los asociados, evitando dejar situaciones sin resolver en el tiempo y que puedan llegar a generar incertidumbre e inconformismo, acarreando así a la imposibilidad de alcanzar uno de los fines primarios del Estado, esto es, lograr la pacífica convivencia social.

En virtud de lo anterior, el término de prescripción extintivo que resulta aplicable es el previsto de manera especial en el artículo 1081 del Código de Comercio, en el cual se dispone que "La prescripción de las acciones que se derivan del contrato de seguro o de las disposiciones que lo rigen podrá ser ordinaria o extraordinaria (...) La prescripción ordinaria será de dos años y empezará a correr desde el momento en 
que el interesado hay a tenido o debido tener conocimiento del hecho que da base a la acción (...) La prescripción extraordinaria será de cinco años, correrá contra toda clase de personas y empezará a contarse desde el momento en que nace el respectivo derecho (...). Estos términos no pueden ser modificados por las partes.". Fallo 2014-0543.

Es preciso observar que como soporte de sus argumentos, la Delegatura para Funciones Jurisdiccionales ha acudido a decisiones emanadas de la Corte Suprema de Justicia, como máximo órgano de la jurisdicción civil, quien en relación con la citada figura jurídica ha señalado que "2.En torno de la genuina interpretación del artículo 1081 del Código de Comercio esta Sala de la Corte tuvo oportunidad de pronunciarse de manera reciente, en sentencia de 3 de mayo de 2000. Al respecto, en síntesis, destacó, lo primero, la peculiaridad del régimen bifronte adoptado por el legislador colombiano en dicha norma, como quiera que al prever la extinción de las acciones derivadas del contrato de seguro o de las normas que lo regulan ya sea por prescripción ordinaria, ora por extraordinaria, se apartó del tratamiento que a la misma materia dan las normas civiles y el derecho positivo de otras naciones, y, tras analizar los antecedentes que precedieron su expedición, estableció que fueron "Razones de indiscutible equidad, que tienen manantial en la seguridad jurídica" las que inspiraron tal reforma, pues por encima de los intereses privados de los intervinientes en el contrato de seguro, que bien pueden verse afectados con la aplicación de una u otra forma de prescripción, se imponía salvaguardar intereses superiores, como son "dotar de certeza las relaciones contractuales" y preservar así el "orden y la paz sociales”.(Corte Suprema de Justicia, Sala de Casación Civil, M.P. Nicolás Bechara Simancas. Exp. 6011 del 19 de febrero de 2002).

\subsection{Interpretación de la prescripción cuando se trata de la cobeer- tura de incapacidad total y permanente}

Es preciso indicar que frente al tema de la cobertura de incapacidad total y permanente, específicamente en lo que tiene que ver con la fecha de conocimiento del dictamen de pérdida de capacidad por parte del demandante, es decir desde cuando el actor tuvo conocimiento de su estado de invalidez, la Delegatura se ha encontrado de acuerdo con la posición de la Corte Constitucional expresada en Sentencia T- 546 de 
2015, en la que se señala que "Para esta Sala, el momento en el que se emite el dictamen de pérdida de capacidad laboral es el momento en el que se reconoce que se configuró el riesgo y el momento a partir del cual el asegurado conoce la circunstancia que le da derecho a exigir el cumplimiento de las obligaciones de la aseguradora y, por ende, es a partir de esta fecha que se deben empezar a contar tanto el término de prescripción ordinaria, como el término de prescripción extraordinaria. Por esta razón, se considera que en los casos ya referidos, no se trató de una inaplicación de términos de prescripción, sino de la determinación de la fecha a partir de la cual debe iniciar a contarse el mismo."

Abonado a lo antes indicado, la Delegatura para Funciones Jurisdiccionales, también ha tomado como suyos aspectos relevantes tratados por la Corte Constitucional en Sentencia T-309A/13, en la cual, resalta que:"El término se debe contar a partir que el actor tuvo conocimiento de la pérdida de capacidad laboral y no desde la fecha de estructuración". Expediente 2016-0127

Es importante destacar que en la Sentencia 2015-2094, señaló la Delegatura que el término de prescripción se debe contar desde que "el asegurado-demandante conoció desde aquel momento sobre la calificación de su pérdida de capacidad laboral, y no antes, pues si bien el dictamen de pérdida de capacidad laboral, establece que tiene fecha de estructuración el 22 de octubre de 2009, mal haría este Despacho computar desde dicha fecha el término de prescripción, pues a pesar de sufrir la dolencia, este no tenía la certeza de que la entidad encargada de calificar su enfermedad, emitiría un concepto por medio del cual se establezca un porcentaje superior al 50\% de pérdida de capacidad laboral. (...)”.

En este sentido, la Delegatura para Funciones Jurisdiccionales, ha recogido múltiples pronunciamientos de las Altas Cortes, que expresan y fijan una posición coherente y clara sobre esta discusión, tal y como se realiza por parte de la Corte Constitucional, en Sentencia C-227 de 2009, en la que dispuso que "Tanto la prescripción como la caducidad son fenómenos de origen legal cuyas características y efectos debe indicar el legislador; estas figuras procesales permiten determinar con claridad los límites para el ejercicio de un derecho. En virtud de la prescripción, en su dimensión liberatoria, se tiene por extinguido un derecho que, por no 
haberse ejercitado, se puede presumir que el titular lo ha abandonado; por ello en la prescripción se tiene en cuenta la razón subjetiva del no ejercicio, o sea la negligencia real o supuesta del titular”.

Para efectos de hacer más lógico su análisis la Delegatura para Funciones Jurisdiccionales ha concluido que la aplicación de dichas instituciones jurídicas, no se vio revocada, interrumpida, suspendida o modificada en virtud de la puesta en marcha de la acción de protección al consumidor, pues tampoco puede entenderse que esta norma deje sin efecto el término previsto por la ley para el ejercicio de las acciones ordinarias que ya hubiere empezado a correr, pues en cualquier caso, en aras de garantizar la seguridad jurídica, la acción de protección al consumidor de que conoce esta Superintendencia, no puede extenderse más allá, de los límites temporales que ha fijado el legislador a través de los diversos tiempos de prescripción aplicables a cada situación jurídica en particular.

Desde otra óptica se ha referido también la Delegatura para Funciones Jurisdiccionales respecto de los Seguros de Vida, y ha fijado una posición clara, como la consignada en el Fallo dictado en el proceso 2013-0553, donde indicó que "es del caso señalar que la fecha de terminación del contrato resulta de meridiana trascendencia para empezar a contar el término de caducidad de la pretensión que incoó la pasiva, puesto que a la luz del contenido normativo del numeral 3 del artículo 58 de la Ley 1480 de 2011 del estatuto del consumidor, "las controversias netamente contractuales," deberán presentarse "a más tardar dentro del año siguiente a la terminación del contrato”, para el caso de marras el plazo final para la interposición de la demanda correspondería a la terminación del contrato de seguro. De esta manera se descarta que el término para la estructuración de la caducidad se cuente en la manera expuesta por el apoderado de (.....) pasiva, esto es, desde el momento en que se tuvo conocimiento de los hechos que se reclaman. Claro lo anterior, para el caso que nos ocupa la señora (.....) falleció el día el $1^{\circ}$ de octubre de 2012, situación que, en el caso que eventualmente se declarara la existencia del contrato aseguraticio que se alega, a partir de tal momento se debería contar el término de caducidad de la acción, por cuanto, ante la configuración del siniestro y consecuente desaparición del riesgo asegurable el contrato de seguro necesariamente terminaría 
por la ausencia de uno de los elementos del contrato, esto es, el riesgo asegurable, lo anterior de conformidad con lo preceptuado en el artículo 1045 del Código de Comercio según el cual "...En defecto de cualquier de estos elementos, el contrato de seguro no producirá efecto alguno."

\subsection{Interrupción de la prescripción}

Frente al tema de la interrupción, la Delegatura para Funciones Jurisdiccionales materializa su posición en dos aspectos a saber: a) si es antes de la entrada en vigencia del artículo 94 del Código General del Proceso o, b) si es en vigencia del mismo.

Dentro del sano entendimiento, manifiesta que si es antes de la entrada en vigencia del Código General del Proceso, es decir en vigencia del Código de Procedimiento Civil, la Delegatura para Funciones Jurisdiccionales de la Superintendencia Financiera de Colombia verificaba si se efectuó la interrupción natural contemplada en el artículo 2539 del Código Civil, ello basándose en el Concepto 2006051752-001 del 22 de diciembre de 2006, dictado por la Superintendencia Bancaria hoy Financiera, el cual señala que, "frente al fenómeno de la interrupción de la prescripción (...) es preciso señalar que en el Código de Comercio no se prevé que el aviso de siniestro o la presentación de la reclamación interrumpa la prescripción, motivo por el cual debemos acudir, en virtud de la remisión expresa consignada en el artículo 822 del mencionado código, a las normas generales del derecho civil para efectos de establecer los lineamientos bajo los cuales procedería la interrupción de la prescripción. En este sentido, el artículo 2539 del Código Civil dispone que la prescripción puede interrumpirse natural o civilmente: "Se interrumpe naturalmente por el hecho de reconocer el deudor la obligación, ya expresa, ya tácitamente".

Ahora, si se trata de una interrupción en vigencia del artículo 94 del Código General del Proceso, ha señalado que "bajo el entendido de que la norma que pretendía destacar lo fuere el último inciso del artículo 94 del mismo compendio, cuya vigencia se dio a partir de octubre de 2012, conforme a las reglas de transición del artículo 627 de código en cita, es 
de añadir que su aplicación está prevista para efectos del requerimiento y no de la interrupción que es la que contempla el Código Civil.

A partir de lo anterior, y con fundamento en el artículo 94 del precitado Código General del Proceso, con la interrupción comienza a correr nuevamente el cómputo del término de la prescripción ordinaria. Posición que se ha mantenido por parte de dicha Entidad en diferentes fallos ${ }^{\underline{8}}$.

\section{CLÁUSUlas abUSivas}

Dentro todo el contexto de la jurisdicción de protección al consumidor, se suma un aspecto bastante importante que integra también el desarrollo de la actividad aseguradora, y es el tema de Cláusulas Abusivas. Frente a este contexto la Delegatura para Funciones Jurisdiccionales ha hecho bastante énfasis en la información que se plasma por parte de las Aseguradoras en sus condiciones, pues se ha evidenciado de forma general que se presenta en los clausulados o condicionados una redacción inadecuada, por lo que dicha entidad ha reforzado en cada uno de sus pronunciamientos la necesidad de contar con una redacción clara y no ambigua, pues de lo contrario de encontrarse frente a un clausulado que no ofrezca garantías mínimas de entendimiento para el asegurado, se habrá de tener por no escrita, como expresamente lo establece el parágrafo del artículo 11 de la Ley 1328 de 2009.

Es de anotar que al respecto, la delegatura ha reiterado lo siguiente "las disposiciones legales en materia de seguros consagran, como regla general, la facultad de las entidades aseguradoras de seleccionar y asumir, salvo que se trate de seguros obligatorios, los riesgos puestos a su consideración, siempre que los mismos resulten legal, técnica y económicamente operaciones factibles, de allí que el artículo 1056 del Código Mercantil preceptúe que "con las restricciones legales, el asegurador podrá, a su arbitrio, asumir todos o algunos de los riesgos a que estén expuestos el interés o la cosa asegurados, el patrimonio o la persona del asegurado." Expediente 2014-0209.

8 Fallos 2013-0553, 2014-0143, 2014-0402, 2014-0448, 2014-0468, 2014-0825, 2014-1468, 20141493, 2015-0224, 2015-2094, 2015-0024, 2016-0739, 2016-1180, 2015-0483, 2015-1506, 20151443, 2015-1688, 2015-0291. 
"Y es precisamente en la aplicación de dicha prerrogativa de indole legal, que las compañías de seguros son autónomas de asumir los riesgos que consideren viables para su actividad social, y es bien sabido que el contrato de seguro se caracteriza por la voluntariedad y que siempre está sujeto a las normas del Código de Comercio y demás concordantes. Sin embargo, no puede perderse de vista que quien determina su contenido y fija previamente las condiciones generales es la aseguradora, para que sus clientes a su elección las acepten o las rechacen, esto por tratarse de relaciones contractuales en masa, que deben desarrollarse de manera estandarizada en su ejecución y operación y que se suscriben siempre entre el mismo contrayente y un gran número de personas". Expediente 2014-0951

Es entonces que dicha regulación se basa en un criterio objetivo y direccionado a la protección del consumidor financiero, sin dejarse de observar también la interpretación y la coherencia de los textos que integran los clausulados depositados en dicha Entidad por las Aseguradoras.

De allí se desprende por tanto la claridad del clausulado que corresponde a un ejercicio propio que efectúa el Asegurador al momento de poner a consideración del Ente de Control el mismo para su aval. En dicha concepción la Delegatura ha indicado que "la importancia de la claridad de las cláusulas particulares contenidas en la póliza, y que éstas sean conocidas por el asegurado y tomador, para que manifieste libremente su consentimiento en señal de aceptación, máxime tratándose de un clausulado elaborado por la aseguradora, que en últimas supera los límites de la consensualidad del contrato de seguro, sin que ello conlleve la convalidación de cláusula abusivas expresamente prohibidas por el legislador al punto que se tendrán por no escritas, como expresamente lo establece el parágrafo del artículo 11 de la Ley 1328 de 2009", pues ello también se constituye en una obligación para una de las partes y que refuerza el sentir equitativo de la relación contractual.

Ello no obsta, para que se deje atrás la integración de la masividad del contrato de seguro en diferentes aspectos, pues el legislador faculta al asegurador para establecer las cláusulas contractuales, incluso aquellas de contenido objetivo, que se constituyen en ley para las partes en virtud del artículo 1602 del Código Civil y 871 del Código de Comercio al disponer que "los contratos deberán celebrarse y ejecutarse de buena fe 
y, en consecuencia, obligarán no sólo a lo pactado expresamente en ellos, sino a todo lo que corresponda a la naturaleza de los mismo, según la ley, la costumbre o la equidad natural".

No solamente, hay que distinguir en sus pronunciamientos no solo lo antes señalado, sino que también se observa que emergen otros aspectos esenciales sobre los cuales se pronuncia la Delegatura, estos son en relación con el tema de los requisitos de los caracteres tipográficos de la póliza, así como de las garantías consignadas en los contratos de seguros ${ }^{2}$ en relación con ello pone de manifiesto lo consagrado en el artículo 184 numeral 2, literal b) del Estatuto Orgánico del Sistema Financiero (EOSF) al incluir que "deben redactarse en tal forma que sean de fácil comprensión para el asegurado. Por lo tanto, los caracteres tipográficos deben ser fácilmente legibles".

En tal sentido, atendiendo la interpretación descrita en el artículo 28 del Código Civil, frente a la expresión "fácilmente legible", aduce que dicha figura quiere indicar que su contenido debe ser sencillo, comprensible, claro, fácil, accesible, o se puede definir como algo "que se pueda leer", instrucción que de igual manera se encuentra contenida en el Título Sexto, Capítulo Segundo, subnumeral 1.2.1 de la Circular Básica Jurídica la cual resalta que "para el adecuado cumplimiento de lo señalado en el artículo 184 numeral 2 EOSF las entidades aseguradoras deben redactar las condiciones del contrato de forma que sean claramente legibles y que los tomadores y asegurados puedan comprender e identificar las definiciones de los riesgos amparados y las obligaciones emanadas del negocio celebrado".

Pretende entonces el Despacho velar por la seguridad, igualdad de garantías entre las partes para acceder libremente a bienes y servicios ofrecidos en el sector financiero y a su vez proteger al consumidor financiero dentro de los límites legales, siendo este el extremo débil en el vínculo contractual e igualmente ofrecer garantías reales para que las compañías se exoneren del pago de la indemnización por inacción en la presentación de la reclamación que da base al hecho.

En su posición jurisprudencial y normativa, la Delegatura ha encontrado dentro de la resolución de sus casos, la existencia sustancial de cláusulas abusivas que dejan en estado de debilidad manifiesta al con-

9 Concepto No. 2003043438-1 de fecha 30 de octubre de 2003 - Superintendencia Financiera de Colombia 
sumidor financiero y por consiguiente el debido reconocimiento a que hubiera lugar en caso de acreditar la realización del riesgo asegurado, al respecto declara dicha entidad ${ }^{10}$ lo siguiente: "Que en consonancia con los Arts. 1036 a 1082 del Código de Comercio es posible vislumbrar la clasificación general de los seguros y las directrices generales que rigen dicha práctica dentro del mercado tal como lo pregona el Título $V$ "Del contrato de seguro" del mismo cuerpo normativo en donde se exponen a) Definición, b) Características generales, c) Elementos esenciales, d) Obligaciones derivadas del contrato de seguro, e) Modalidades de aseguramiento, f) El siniestro, g) subrogación, g) Prescripción, i) Terminación del contrato de seguro, etc. Pese a que en los Artículos ya citados con antelación se encuentra desarrollada ampliamente el tema del contrato de seguro".

Y es así que el Gobierno Nacional ha dictado normas que determinan los aspectos técnicos pertinentes. Para garantizar la prohibición de utilización de cláusulas abusivas en contratos, disponiendo que las cláusulas o estipulaciones contractuales que se incorporen en los contratos de adhesión, que contengan lo siguiente se consideran abusivas:

a) Prevean o impliquen limitación o renuncia al ejercicio de los derechos de los consumidores financieros.

b) Inviertan la carga de la prueba en perjuicio del consumidor financiero.

c) Incluyan espacios en blanco, siempre que su diligenciamiento no esté autorizado detalladamente en una carta de instrucciones.

d) Cualquiera otra que limite los derechos de los consumidores financieros y deberes de las entidades vigiladas derivados del contrato, o exonere, atenúe o limite la responsabilidad de dichas entidades, y que puedan ocasionar perjuicios al consumidor financiero.

e) Las demás que establezca de manera previa y general la Superintendencia Financiera de Colombia.

Siendo enfática la Delegatura en la necesidad de blindar la relación bilateral que rige por regla general todo tipo de contratos, aún más cuando

10 Expediente No. $2014-0469$ 
se observa en él una de las características más destacables la "Adhesión", como elemento esencial que rodea el vínculo entre el Asegurador y el Asegurado, por lo que, hace referencia al concepto del Académico Fernando Hinestroza en su artículo "El deber de sinceridad del tomador del seguro en su declaración del estado del riesgo" $" 1$, en el cual plantea que cuando la declaración sobre el estado del riesgo se hace a través de un formulario elaborado por la Aseguradora, los hechos y circunstancias que son materia del mismo han de ser los relevantes para la apreciación del riesgo, añadiendo que "el cuestionario contenido en el formulario es la oportunidad por excelencia, para algunos única, que tiene el asegurador para indagar sobre lo que le interesa con relación al estado del riesgo, o sea que el formulario y su contestación son los puntos de referencia ciertos y concretos a propósito del comportamiento de uno y otro de los contratantes, para el juzgamiento de su proceder y los efectos consiguientes."

De conformidad con lo anterior, y de revisar las providencias dictadas a lo largo de los años 2012 a 2016 y parte del 2017, la Delegatura constante y reiteradamente ha concluido que si el clausulado contiene clausulas que por su escritura son abusivas por contener limitaciones o renuncias de derechos por parte de los consumidores, invertir la carga de la prueba, incluir espacios en blanco sin regulación, dichas disposiciones se habrán de tener como no escritas, posición que como se indicó, no ha variado, tal y como se advierte de las Sentencias 2013-0529, 2014-0917, 2013-0049, 2014-0741, 2015-0086, 2014-0854 y 2016-1422.

\section{RETICENCIA E INEXACTITUD}

Dentro del estudio del alcance y aplicabilidad de la reticencia contenida en el artículo 1058 del Código de Comercio, frente a la negativa del reconocimiento de una indemnización, se ha encontrado que la Superintendencia Financiera de Colombia a lo largo del desarrollo de su facultad jurisdiccional ha venido realizando un análisis imparcial y objetivo en cada uno de sus pronunciamientos y decisiones, aplicando en equidad la procedencia o no de la nulidad relativa del contrato de seguro, en razón

11 Revista Ibero-Latinoamericana de Seguros No. 27, de diciembre de 2007 
a la configuración de la fenómeno de "Reticencia" de acuerdo con las situaciones que se establezcan.

Es de resaltar que a través de su facultad jurisdiccional dicho Ente ha efectuado un análisis homogéneo basado en las características que rodean la declaratoria de nulidad de un Contrato de Seguro en razón al ocultamiento de la información necesaria para la calificación de riesgo que asume las aseguradoras; así como frente a los principios que rigen el seguro, como lo es el principio de la buena fe de las partes intervinientes en dicha relación contractual. Posición que soporta en decisiones emanadas de la Honorable Corte Constitucional ${ }^{12}$, e igualmente, en conceptos proferidos por esa misma Superintendencia ${ }^{13}$ en el que se hace referencia a las estipulaciones contenidas en la declaración de asegurabilidad cuando esta es suministrada.

En sus intervenciones ha reiterado dicha Superintendencia que "en el ramo de vida, adquiere especial relevancia el postulado de la buena fe de las partes del contrato de seguros", pues como lo señala el juzgador "la exigencia de obrar de buena fe es una obligación bilateral de los contratantes", haciendo alusión a que ninguna de las partes debe actuar con la intención de sacar provecho irregular de su posición contractual ${ }^{14}$.

Así mismo, hay que resaltar que durante el desarrollo de su facultad jurisdiccional la Superintendencia Financiera de Colombia ha sido muy clara en su posición frente al tema de la "Reticencia", ya que sea para conceder el derecho a las Aseguradoras como a los Asegurados, siempre valorando conforme a derecho y a lo dispuesto en la ley, las razones que conllevan a la aplicabilidad o no de la misma, sin dejar de lado fundamentos importantes como que el Contrato de Seguro se caracteriza por la voluntariedad y que siempre está sujeto a las normas del Código de Comercio y aquellas que lo adicionan o modifican, sin tampoco inobservar que en el Contrato de Seguro quien determina unilateralmente y fija previamente las condiciones generales es la Compañía de Seguros y es por ello que el legislador colombiano faculta al Asegurador para establecer las cláusulas contractuales, en virtud del mismo ordenamiento legal y fundando su concepto en que "los contratos deberán celebrarse y ejecutarse de buena fe y, en consecuencia, obligarán no sólo a lo pactado expresamente en ellos, sino a todo lo que

12 Sentencia C-232/97 Régimen Rescisorio Especialmente Contemplado en el Artículo 1058 del Código de Comercio, T-086-2012 y T-171 de 2003 (principio de la buena fe)

13 Concepto2010080188-001 del 17 de diciembre de 2010

14 Expediente 2016-0219 - Radicación 201614949 de fecha 10 de marzo de 2017 
corresponda a la naturaleza de los mismos, según la ley, la costumbre o la equidad natural”'15.

Es preciso señalar que cuando se ve superado el término de 5 años contados a partir de la declaración de asegurabilidad y sobre todo en pólizas de salud que el deterioro del estado de salud es propio del riesgo asegurado, la compañía no podrá alegar la reticencia "En los anteriores términos, siendo que la demandante era cliente de la aseguradora, para un mismo seguro desde el año 1993, no puede hablarse tampoco de una reticencia, es decir, una conducta de mala fe de su asegurada, cuando era claro para las partes y más para quien asume el riesgo, que el trascurrir del tiempo conllevaba un eventual deterioro en el estado del mismo, cuya carga no corresponde al consumidor-asegurado, en los términos del artículo 1060 citado y, en los términos del 1058, no resulta novedad alguna para la aseguradora y excluye el elemento doloso o de mala fe que requiere la reticencia para generar la sanción previstas por esta última norma." Expediente 2014-0963

Es de resaltar frente a las actuaciones realizadas por la Superintendencia Financiera de Colombia, que siempre ha valorado y sopesado en sus posiciones la importancia de la manifestación del principio de la buena fe de quienes intervienen en el perfeccionamiento de todos los actos y contratos mercantiles, siendo acuciosa al momento de exponer sus consideraciones, de manifestar dentro de la órbita jurídica, la importancia de cada uno los postulados legales y constitucionales en la materia ${ }^{16}$

De igual manera, también en muchas de sus consideraciones se observan aspectos relevantes como el diligenciamiento de la declaración de asegurabilidad, fijando una posición clara, en la objetividad del documento y que ello no deja de lado que la reticencia se origina en el conocimiento que tiene el candidato a asegurado, sobre sus condiciones exactas de salud y las razones por las cuales, no manifiesta sinceramente sus condiciones o estas son inexactas, pero a su vez destacan dentro de sus fundamentos que tampoco pueden considerarse que no cualquier omisión puede conllevar a una nulidad relativa del contrato de seguro, más aún cuando debe siempre observarse el deber de información que se impone al tomador del seguro, o al asegurado $\frac{17}{}$.

15 Fallo 14 de marzo de 2017 Expediente 2016-0959 - Rad. Interno 2016057577

16 Corte Constitucional Sentencia T-227/2016

17 CSJ - Sala Casación Civil, Sent. 16 diciembre 2016, MP Álvaro Fernando García Restrepo - Artículo 1039 del Código de Comercio 
Así las cosas, la Delegatura no solo funge como protectora de las normas legales, sino que también ha encontrado un respaldo de la doctrina y de la jurisprudencia, que le ha ayudado a fortificar las disposiciones contractuales pactadas por las partes, pues analiza desde un punto de vista critico los factores que constituyen la inexactitud, la reticencia propiamente dicha y también la información no sincera emanada del asegurado frente a la causa del siniestro, a efectos de determinar la viabilidad de la configuración de la sanción legal, que no es otra que la nulidad relativa del contrato de seguro, por demás no, es otra, que la relevancia de la información no suministrada u ocultada con la génesis misma del siniestro reportado, diferenciando de manera sustancial si dicha omisión de manifestación de la información, constituye por sí sola, la base para establecer el argumento de reticencia, y por consiguiente, la presencia de la sanción establecida en el artículo 1058 del Código de Comercio ${ }^{18}$.

Dentro de su concepción crítica, resalta la potestad que da el artículo 1056 del Código de Comercio al Asegurador, lo que se constituye en la determinación de los riesgos cuya materialización entran a ser los amparados por el Asegurador, al momento del otorgamiento de la respectiva cobertura, y que va en consonancia con las condiciones particulares y generales del seguro contratado, que al ser aceptadas por el tomador del seguro y aceptadas por tanto por la Compañía de Seguros se constituye en ley para las partes, exista o no limitación de los riesgos que se asumen.

Es de precisar que la Superintendencia Financiera de Colombia no se aparta dentro de su facultad jurisdiccional de los matices de protección al consumidor y deber de información a los usuarios por parte de las Compañías de Seguros, pues en sus argumentos siempre hay vinculación de estos aspectos rectores en la relación contractual que se debate en torno a posiciones propias en cada uno de los casos, considerando en muchos aspectos la protección especial que debe darse al consumidor financiero en virtud del artículo 78 de la Constitución Política de Colombia $\frac{19}{19}$ y es por ello, que en muchos de estos casos, están llamadas a prosperar las pretensiones a los asegurados, cuando se encuentra asidero legal y constitucional que demuestra la vulneración del consumidor frente a la parte dominante.

Igualmente se soporta sus fundamentos en el concepto No.2010080188-

18 Corte Constitucional Sentencia T-222/14 (CSJ- Fallo del 1 de septiembre de 2010)

19 Corte Constitucional Sentencia T-222/14 (CSJ- Fallo del 1 de septiembre de 2010) 
001 del 17 de diciembre de 2010, de la Superintendencia Financiera de Colombia en la que se indica que "[l]a declaración del estado del riesgo puede darse de dos maneras: mediante la absolución de un cuestionario que la aseguradora suministre en el cual se formulan preguntas especificas, o bien a través de una declaración espontánea en la cual el tomador o asegurado informa, según su criterio, los hechos o circunstancias que rodean el riesgo; pero en uno y otro caso la declaración debe ser sincera y exacta, toda vez que la ley sanciona el desconocimiento de este precepto, así: 2.1 Si la declaración se hizo con sujeción a un cuestionario y las respuestas al mismo son inexactas, por cuanto son falsas o erróneas, o son reticentes, en la medida que ocultan o encubren una situación, y tales manifestaciones son relevantes para el contrato dado que los hechos sobre que versan eran o debían ser conocidos por el tomador y que de haber sido conocidos por el asegurador lo hubieran retraído de celebrar el contrato o inducido a estipular condiciones más onerosas; existe un vicio de nulidad relativa que afecta la validez del mismo"

En virtud de lo anterior, cuando en el proceso se advierta que la defensa de la entidad esta enfilada a que se declare que el asegurado fue reticente, y de encontrarse probado, el Despacho Jurisdiccional declarará la nulidad relativa del contrato, lo que conlleva consecuentemente ordenar a título de sanción, que la compañía de seguros retenga la totalidad de las primas cuando la reticencia o la inexactitud han sido las causas de la rescisión del contrato.

Si bien dentro de los requisitos de asegurabilidad, es claro que se debe informar todos los parámetros que se salgan de lo normal. Por lo que es un requisito fundamental para que la aseguradora asuma el riesgo con lo informado en el formulario. Cabe resaltar que al ser una póliza agrupadora y por la masividad de los asegurados, es de difícil acceso para la aseguradora solicitar exámenes médicos a cada uno de ellos, por lo que se parte de la buena fe para la inclusión del mismo en la póliza, aunque esto no lo exime de solicitar los respectivos exámenes.

De igual manera, incorpora en sus actuaciones la correcta línea de acudir también a la visible diferencia que en gran medida puede observarse en cuanto a la desproporción de cargas entre las partes contratantes, acudiendo de forma obligatoria a dilucidar sobre la trascendencia de las prácticas de protección propias por parte de los consumidores, incorporando a su es- 
tudio lo dispuesto en la Ley 1328 de 2009, Título I - Artículo 6 - Literales b) y d), siempre en busca de la equidad, destacando que: "Informarse sobre los productos o servicios que piensa adquirir o emplear, indagando sobre las condiciones generales de la operación; es decir, los derechos, obligaciones, costos, exclusiones y restricciones aplicables al producto o servicio, exigiendo las explicaciones verbales y escritas necesarias, precisas y suficientes que le posibiliten la toma de decisiones informadas" y "Revisar los términos y condiciones del respectivo contrato y sus anexos, así como conservar las copias que se le suministren de dichos documentos".

La mencionada Entidad a lo largo de su labor siempre se ha caracterizado por hacer prevalecer el marco normativo y jurisprudencial frente a las condiciones de ejecución del Contrato de Seguro, buscando con ello la integración de manera objetiva de todos los aspectos en busca de la mayor equidad posible en sus actuaciones.

La labor de juez le ha permitido a la Delegatura ahondar en temas de gran transcendencia, como lo es, la configuración de la reticencia a las luces de lo preceptuado en el artículo 1058 del Código de Comercio, y frente a la posición de las Altas Cortes (Corte Constitucional y Corte Suprema de Justicia), en torno a la materialización de la misma y el alcance y relevancia de este fenómeno que con el paso del tiempo ha ido creciendo en forma abismal en el trámite de las reclamaciones no solo con cargo a seguros de vida sino también en el campo de los seguros generales o de daños.

\section{SEGURO DE VIDA - VIDA GRUPO DEUDORES}

En las Sentencias relacionadas con el tema de Seguro Vida Grupo Deudores, la Delegatura inicia con el estudio del seguro en general, para después pasar con el ramo de vida en particular, junto con el régimen que gobierna dicho seguro, indicando que “(...) puede ser tomado por cuenta de un tercero determinado o determinable, pero al asegurado le corresponden las obligaciones que no puedan ser cumplidas más que por él mismo, al tenor de lo dispuesto por el artículo 1039 del ordenamiento mercantil" que "sobre la entendibilidad de las condiciones para el tomador del con- 
trato de seguro, el numeral $2^{\circ}$ del artículo 187 del Estatuto Orgánico del Sistema Financiero, en concordancia con el subnumeral 1.2.1 del capitulo segundo del título sexto de la circular básica jurídica, establece que las mismas deben estar consignadas de manera que"(...)"sean claramente legibles y que los tomadores y asegurados puedan comprender e identificar las definiciones de los riesgos amparados y las obligaciones del negocio celebrado".

Señala dentro de sus apreciaciones y fundamentos que el mismo corresponde a un seguro de grupo o colectivo, por medio del cual la Aseguradora se compromete a responder ante la ocurrencia de un siniestro que afecte a un número plural de personas naturales vinculadas por una relación contractual con una misma persona jurídica, por lo que retoma en el estudio del mismo elementos, situaciones y circunstancias de toda índole. (Fallo 2014-0450, 2014-0469, 2015-0024)

Indica a su vez que el seguro al tenor de lo señalado en el artículo 1036 del Código de Comercio "(...) es un contrato consensual, bilateral, oneroso, aleatorio y de ejecución sucesiva", celebrado entre el asegurador "o sea la persona jurídica que asume los riesgos, debidamente autorizada para ello con arreglo a las leyes y reglamentos" (artículo 1037), y el tomador, es decir, "la persona que, obrando por cuenta propia o ajena, traslada los riesgos", relación negocial que cuenta con unos elementos esenciales, los cuales ante su ausencia, el contrato no producirá efectos; elementos que se encuentran enunciados en el artículo 1045 del Código de Comercio, a saber, interés asegurable, riesgo asegurable, prima o precio del seguro, $y$ finalmente, la obligación condicional, consistente esta última en que una vez consumado el riesgo asumido por la compañía de seguro, surge para la misma la obligación de indemnizar o pagar la suma asegurada según corresponda (artículo 1054 ibídem).

Adicionalmente, en otras decisiones ha resaltado que "De allí, la importancia de la claridad de las clausulas particulares contenidas en la póliza, y que estas sean conocidas por el asegurado y tomador, para que manifieste libremente su consentimiento en señal de aceptación, máxime tratándose de un clausulado elaborado por la aseguradora, que en ultimas supera los límites de consensualidad del seguro" (...) "De la mano con lo anterior, el contrato de seguro se caracteriza por la voluntariedad y que siempre está 
sujeto a las normas del Código de Comercio y demás concordantes. Sin embargo, no puede perderse de vista que quien determina unilateralmente su contenido y fija previamente las condiciones generales es la aseguradora, para que sus clientes a su elección las acepten o las rechacen, esto por tratarse de relaciones contractuales en masa, que deben desarrollarse de manera estandarizada en su ejecución y operación y que se suscriben siempre entre el mismo contrayente y un gran número de personas, sin que ello conlleve la convalidación de cláusula abusivas expresamente prohibidas por el legislador al punto que se tendrán por no escritas, tal y como lo establece el parágrafo del artículo 11 de la Ley 1328 de 2009."

Ahora bien, dentro del valor probatorio a lo aportado en el trámite procesal, resalta la importancia del dictamen de pérdida de capacidad laboral, señalando en múltiples oportunidades que "al plenario se allegaron dos dictámenes emitidos por dos Instituciones Prestadoras de Servicios distintas, los cuales difieren sustancialmente entre sí respecto de los porcentajes de pérdida de capacidad laboral diagnosticados al señor (.....), por lo que, habiéndose allegado ambos en las oportunidades procesales establecidas por la ley, deberá la Delegatura inclinarse por aquel emitido por MEDICO SALUD, por cuanto es dicha institución la encargada de la prestación de servicio médicos a los docentes, conforme así lo manifestó la Secretaria de Educación del Meta y la Superintendencia Nacional de Salud. Aunado a lo anterior, el dictamen emitido por MEDICOL SALUD, contrario al aportado por la pasiva, tuvo en consideración no solo la historia clínica del señor (....), sino además “(...) el concepto de salud ocupacional, exámenes paraclínicos, epicrisis de la historia clínica". En el mismo sentido, el dictamen realizado por la Aseguradora, pese a no estar pactado en el contrato y con el cual se pretende desvirtuar el dictamen realizado por quien está a cargo como entidad prestadora de salud del Magisterio, no tiene la competencia asignada por la ley ni por el contrato, encontrando que es el diagnostico hecho por MEDICOL SALUD el que cuenta con mayores elementos de juicio para realizar, de manera más acertada, el diagnóstico de la pérdida de capacidad laboral. En tales términos, para la Delegatura, el aludido dictamen presenta la fuerza demostrativa suficiente a fin de acreditar el cumplimiento de la ocurrencia del siniestro, esto es, el estado de incapacidad del señor (....) y que el mismo se produjo en vigencia de la póliza, por lo que se encontró acreditado el artículo 1077 del Código de Comercio. (Fallo 2014-0917). 
Dentro del desarrollo de sus consideraciones ha tocado temas y aspectos relevantes como la cobertura de Incapacidad Total y Permanente, indica que para efectos de analizar las cargas de las partes, de conformidad con el artículo 1077 del Código de Comercio, al asegurado le corresponde "demostrar la ocurrencia del siniestro, así como la cuantía de la pérdida, si fuere el caso", en tanto que "el asegurador deberá demostrar los hechos o circunstancias excluyentes de su responsabilidad" y que "(...) el siniestro corresponde al estado de invalidez del asegurado o su estado incapacidad total y permanente de acuerdo con lo pactado en el contrato y, en tal evento, conforme lo previsto en el artículo 1077 del Código de Comercio, al asegurado le bastará con demostrar su ocurrencia del siniestro (incapacidad total y permanente), siempre y cuando el medio probatorio elegido sea idóneo, conducente y pertinente para demostrar claramente tales hechos, y que este se haya presentado durante la vigencia del seguro. A la compañía le corresponderá, en términos del mismo artículo "demostrar los hechos o circunstancias excluyentes de su responsabilidad" ello con fundamento en lo señalado en el concepto 2015016246-002 del 27 de abril de 201Ancla5 emanado de dicha Superintendencia. Fallo 2014-0529

Bajo este precepto, en lo que tiene que ver con la prueba de la pérdida de capacidad laboral, cuando nos encontramos frente a pólizas de docentes, de conformidad con lo previsto en el Decreto 917 de 1999 (hoy decreto 1507 de 2014) y al artículo 18 inciso final de la Ley 1562 de 2012, los docentes pertenecen a un régimen especial y exceptuado en cuanto al reconocimiento de pérdidas de capacidad laboral, como lo es el del Magisterio. La Corte Constitucional, en reciente sentencia T - 902/13, M.P. María Victoria Calle Correa, es clara al confirmar que "respecto de las personas que hacen parte del Fondo Nacional de Prestaciones del Magisterio, se ha dicho que los dictámenes de pérdida de capacidad laboral los debe hacer en primera instancia la entidad con la cual se tienen contratados los servicios médicos asistenciales, y en segunda instancia las Juntas Regionales de Calificación (...) Esa asignación de competencias desarrolla la eficiencia del sistema de seguridad social, porque permite que los recursos administrativos se utilicen de la manera más óptima posible. Por una parte, entidades especializadas, realizan los dictámenes del personal con régimen excepcional, repartiendo la competencia de calificación entre aquellas instituciones que mejores atributos tienen para conocer las dificultades de sectores de la economía que necesitan tratamiento diferente. Y de otra parte, aliviana la carga de trabajo de las Juntas Regionales de Calificación y de la Junta Nacional de Calificación, en tanto las personas que hacen parte de regímenes exceptuados 
sólo pueden acudir a ellas en segunda instancia, si existe alguna controversia en torno al nivel de discapacidad otorgado, y ningún caso pueden acceder a Junta Nacional como medio de revisión excepcional." Fallo 2016-0127

De igual manera, precisa que frente al alcance de la cobertura de Incapacidad Total y Permanente, donde se señala la posibilidad de que el asegurado pueda realizar cualquier otra ocupación u oficio remunerativo, la Delegatura ha señalado que la pérdida de capacidad laboral debe ser analizada desde la imposibilidad de ejercer la actividad de la cual derivada sus ingresos, es decir la docencia (2014-0917), ello con respaldo en el pronunciamiento de la Corte Constitucional en sentencia T - 490/09, M.P. Luis Ernesto Vargas Silva, cuando señaló que "Al obviar el reconocimiento y pago del valor asegurado por concepto del amparo denominado incapacidad total permanente, la cual en efecto se estructuró desde el 16 de noviembre de 2007 según revela el acervo documental allegado por el accionante con su escrito de tutela, se vulneró el derecho fundamental al mínimo vital de una persona discapacitada, en estado de indefensión y con debilidad manifiesta, habida cuenta que el criterio de "cualquier trabajo remuneratorio" debe limitarse a la actividad o destreza que ejercía el asegurado, en este caso concreto del oficio de fumigador por más de 20 años. Es que se torna difícil exigir a una persona discapacitada de 44 años de edad con bajo nivel de escolarización y con una única actividad productiva a lo largo de su vida, que de un momento a otro aprenda otra labor en aras de brindarse un sostenimiento digno para él y su familia; por eso, esta Sala considera que la interpretación de la cláusula contractual en debate, debe ceñirse a los principios $y$ valores constitucionales, que partiendo de un criterio de equidad permita al operador decidir teniendo en cuenta no solo las prescripciones legales, sino los efectos concretos de su decisión en las partes".

No deja de lado en pronunciarse la Superintendencia Financiera sobre temas relevantes como la revocatoria de las pólizas colectivas ha fundado sus argumentos atendiendo a lo señalado en el concepto 1999055751-2 de Octubre 19 de 1999 emanado de dicha entidad, el cual precisa que "(...) así las cosas y acorde con la bilateralidad que caracteriza al contrato de seguro se puede inferir que la revocación unilateral del mismo, prevista en la ley, sólo es procedente en la medida que la manifestación de voluntad, en este sentido, provenga de quien contractualmente se encuentra vinculado y se dirija a aquel que encontrándose en la misma situación jurídica se reputa igualmente parte. Tal es el sentido de la previsión consignada en el artículo 1071 del Código de 
Comercio, la cual, al emplear el término asegurado, presupone concurrente en el mismo sujeto el carácter de tomador, de manera que cuando dicha identidad no se produzca, ha de ser a éste a quien se comunique la decisión de finalizar el contrato de seguro... No obstante lo anterior, el tomador de la póliza debe comunicar esta situación a los asegurados, pues de lo contrario podría incurrir en una responsabilidad civil frente a éstos". Encontrando con ello, un criterio fijo y radical frente a dicha circunstancia.

Así las cosas, en un contexto general recalca en que las pólizas de vida grupo deudores por lo general y en su mayoría van atadas a un crédito por lo que de esa manera ya genera un vínculo contractual con el asegurador de manera indirecta, no sin dejar de lado que éste pueda conocer el estado de salud del asegurado al momento de acceder a un crédito, por lo que puede concluirse, que para este tipo de pólizas se actúa en pro de declarar sinceramente el estado de salud para el momento de la celebración del contrato.

Principalmente en el ramo de Vida y a lo que refiere al contrato de seguro, se tiene que el principio de la buena fe, es la base de las relaciones contractuales, por lo que sus actuación deben ser de total cumplimiento de la ubérrima bona fides. A las anteriores conclusiones se llega de analizar múltiples fallos proferidos por el Entidad a través de sede jurisdiccional 20 .

Finalmente, es claro que a través de este tipo de Proceso Declarativo se ha buscado por parte del legislador colombiano, condensar en cabeza de una Entidad que idoneidad labores propias del juez y así minimizar en gran medida las trabas de acceso a la justicia que involucran tiempos y desgastes en procedimientos sencillos y ajustados a derecho. En este aspecto, la misma Delegatura ha señalado que "no obstante, como lo pretendido a través de este proceso declarativo es dejar sin efectos las razones que llevaron a la aseguradora a objetar la reclamación que le fuera presentada, declaración para lo cual resulta competente esta Delegatura, atendiendo que se trata del cumplimiento y ejecución de obligaciones derivadas del contrato de seguro, procederá la Delegatura a analizar el acervo probatorio a efectos de resolver la controversia sometida a su consideración".

$20 \quad 2013$ - 0543, 2012-0027, 2013-0335, 2014-0419, 2015-0189, 2013-0707, 2013-0746, 2013-800, 2014-0005, 2014-0006, 2014-0019,2014-0038, 2014-0059, 2014-0073, 2014-0082, 2014-0143, 2014-0169, 2014-0209, 2014-0221, 2014-0409, 2014-0419, 2014-0450, 2014-0469, 2014-0529, 2014-0545, 2014-0634, 2014-0689, 2014-0717, 2014-0726, 2014-0734, 2015-0024 
En consideración a lo anterior, se ha de indicar que en materia de seguros de vida, campea la buena fe, el deber de información, y los clausulados entregados al asegurado; el tema de la reticencia es primordial. La posición no ha presentado variaciones, sin embargo, se pueden ver pocos cambios en la técnica y en la redacción entre los diferentes fallos pero la posición en temas relacionados con controversias frente a seguros de vida y grupo deudores, no ha variado.

En consecuencia, como resultado del ejercicio académico de análisis realizado, es posible llegar a las siguientes conclusiones conforme las posiciones adoptadas por la Delegatura para Funciones Jurisdiccionales de la Superintendencia Financiera de Colombia a lo largo de los casi 6 años de su ejercicio Jurisdiccional, encontrando providencias expresadas de manera lógica, congruente, buscando un equilibrio en sus decisiones y fundamentos que en la gran mayoría de los casos no se han apartado del estudio y discrecionalidad de las Altas Cortes, pues estas han sido pilar de su fallos.

Por otro lado, es importante destacar que dicha facultad jurisdiccional ha sido motivo de integración con sus demás competencias administrativas, y que ha buscado siempre que su gestión sea acorde con la estructura y necesidades del entorno jurídico, basada en una misión participativa e integrada a las distintas tendencias jurídicas que sobre los temas a cargo han podido a la par desarrollar la Corte Suprema de Justicia y la Corte Constitucional.

Es de reconocer que la gestión de la Delegatura para Funciones Jurisdiccionales ha sido un factor de ventaja jurídica dentro del enfoque de sus facultades de protección al consumidor y ha podido realizar una actuación completamente diferente a las desarrolladas a través del tiempo, de inspección, vigilancia y control, cuya base es netamente administrativa y que en el campo que ha incursionado ha sido generoso el aporte y que a su vez ha ido contribuyendo en el desarrollo jurisprudencial al integrarse con la función judicial ordinaria, haciendo parte del engranaje jurídico dentro de la tendencia de cambio que ha forjado el Legislador Colombiano, buscando con ello una mentalización y una colaboración total entre todos los agentes del estado como operadores logísticos especializados, que redunda en un papel clave para la gestión judicial. 
Sin embargo, se ha notado que la jurisprudencia de la Delegatura para Funciones Jurisdiccionales ha demostrado tener una línea argumentativa similar al de la Corte Constitucional y Corte Suprema de Justicia que puede ser calificada como proteccionista del derecho de consumo, pues se considera que ha sido direccionada a promover la protección del consumidor por una carencia del goce efectivo de sus derechos fundamentales que día a día se ven expuestos a su vulneración por parte del Sector Asegurador, por lo que se concluye que dicha actividad debe gozar de una atención primordial, razón de ser de los fallos proferidos.

En lo que tiene que ver con la protección al consumidor, es importante señalar que las decisiones que ha adoptado respetan tanto el interés público que cobija el ejercicio de la actividad financiera, de otra parte, no se aparta de las decisiones de la Corte Suprema de Justicia, sin embargo, existen casos que se han fallado teniendo en cuenta las posturas de la Corte Constitucional, circunstancia que a nuestro sentir no afecta las diferentes decisiones que con un grado alto de tecnicismo se han tomado, dada su calidad de Juez especializado.

Así mismo, se recalca que en las decisiones se busca un protección al consumidor pero desde la perspectiva del cumplimiento y ejecución de las obligaciones propias del contrato de seguro, soportado en las diferentes normas sustanciales que enmarcan la actividad, pudiendo las compañías demandadas en todos los casos lograr acreditar la ausencia o los eximentes de responsabilidad con una debida actividad probatoria.

\section{BIBLIOGRAFÍA}

Constitución Política de Colombia. https://www. Notinet .com.co

Código General del Proceso. https://www.not inet.com .co

Código de Comercio. https://www.not inet .com.co

Jurisdicción ordinaria sala de casación civil - sentencia del 30 de abril de 2009 
Circular Básica Jurídica, Título I, Cap. VI. Superintendencia Financiera de Colombia. https://www.super financiera.g ov.co

Concepto No. 2003043438-1 de fecha 30 de octubre de 2003 - Superintendencia Financiera de Colombia. https://www .superfinan ciera.g ov.co

Concepto No. 2010080188-001 de fecha 17 de diciembre de 2010 - Superintendencia Financiera de Colombia. https://www.superfinanciera. gov.co

Corte Constitucional, Sala Plena, octubre 15 de 1997, RAD: D-1485, MP Jorge Arango Mejía

Corte Constitucional, Sala Quinta de Revisión, febrero 24 de 2003, RAD: T-656821, MP Rodrigo Escobar Gíl

Corte Constitucional, Sala Tercera de Revisión, julio 23 de 2009, RAD: T-2222600, MP Luis Ernesto Vargas Silva

Corte Constitucional, Sala Primera de Revisión, enero 20 de 2012, RAD: T-3182540, MP María Victoria Calle Correa

Corte Constitucional, Sala Quinta de Revisión, marzo 13 de 2013, RAD: T-36864396, MP Jorge Iván Palacio Palacio

Corte Constitucional, Sala Novena de Revisión, abril 2 de 2014, RAD: T-4143382 T-4148791 T-4173384, MP Luis Ernesto Vargas Silva

Corte Constitucional, Sala Sexta de Revisión, mayo 11 de 2016, RAD: T-5227083, MP Jorge Iván Palacio Palacio

Corte Suprema de Justicia, Sala de Casación Civil y Agraria, mayo 2 de 2000, RAD: 6291, MP Jorge Santos Ballesteros

Corte Suprema de Justicia, Sala de Casación Civil, abril 30 de 2009, RAD:25899319399219990062901, MP Pedro Octavio Munar Cadena

Corte Suprema de Justicia, Sala de Casación Civil, septiembre 1 de 2010, 
RAD: 05001310300120030040001, MP Edgardo Villamil Portilla

Corte Suprema de Justicia, Sala Casación Civil, diciembre 16 de 2016, RAD: SC18563, MP Álvaro Fernando García Restrepo

Tribunal Superior del Distrito Judicial de Bogotá, Sala Civil, enero 21 de 2016, RAD: 11001319900120150118501 , MS Julia María Botero Larrarte

Superintendencia Financiera de Colombia, Delegatura para Funciones Jurisdiccionales, enero 18 de 2013, RAD: 20120027

Superintendencia Financiera de Colombia, Delegatura para Funciones Jurisdiccionales, noviembre 19 de 2013, RAD: 20130335

Superintendencia Financiera de Colombia, Delegatura para Funciones Jurisdiccionales, diciembre 13 de 2013, RAD: 20130130

Superintendencia Financiera de Colombia, Delegatura para Funciones Jurisdiccionales, mayo 29 de 2014, RAD: 20130543

Superintendencia Financiera de Colombia, Delegatura para Funciones Jurisdiccionales, agosto 12 de 2014, RAD: 20140143

Superintendencia Financiera de Colombia, Delegatura para Funciones Jurisdiccionales, noviembre 14 de 2014, RAD: 20140409

Superintendencia Financiera de Colombia, Delegatura para Funciones Jurisdiccionales, marzo 13 de 2015, RAD: 2014-0846

Superintendencia Financiera de Colombia, Delegatura para Funciones Jurisdiccionales, enero 28 de 2014, RAD: 20130345

Superintendencia Financiera de Colombia, Delegatura para Funciones Jurisdiccionales, marzo 10 de 2017, RAD: 201614949

Ríos Ossa Roberto, La Declaración del Riesgo en el Seguro de Vida, Deber de Informar y de Informarse, Revista Ibero-Latinoamericana de Seguros Volumen 26, No. 47, 107-118 (2017) 